\title{
Building Performance Simulation Supporting Typical Design Activities: The Case Of 'Reference Pictures'
}

\author{
Steffen Petersen ${ }^{1}$, Pil Brix Purup ${ }^{2}$ \\ ${ }^{1}$ Aarhus University Department of Engineering, Aarhus, Denmark \\ ${ }^{2}$ Niras A/S, Allerød, Denmark
}

\begin{abstract}
Seeking inspiration in pictures of already realised building designs is a common activity amongst architects in the early stage of building design. This paper describes a prototype of a façade design database with parametric models connected to BPS tools. The intention is to facilitate the time consuming transition from a static reference picture to a working model for design development. Feedback from practicing architects on the prototype indicates that building designers could benefit from having access to such a database. The feedback also led to valuable suggestions for making the database even more relevant to design practice.
\end{abstract}

\section{Introduction}

There are research-based efforts focusing on proposing procedures for enhancing efficient use of building simulation tools for proactive performance prediction in the early design stage, e.g. Petersen (2011), Attia et al (2012), and Gerber and Lin (2014), to cite but a few. However, to our knowledge, there is no research-based evidence on whether any of such procedures are actually being adopted by designers in professional design practice; our notion is that it is rare. A reason might be that current proposals for procedures and methodologies are only assumptions of, or they interprets wrong, what architects actually need (Bleil de Souza, 2011). Petersen et al. (2014) reviewed recent studies regarding the use of building simulation tools in the early design phase and conducted their own qualitative survey to identify the barriers for using simulation tools in the early design phase. The overall conclusion was that architects are interested in using output from building simulation tools in the early design phase to make informed design decisions but only if the provision of this information (use of building simulation) is conformed to fit their design process.

The above realisations was main arguments for a more indepth investigation on 'how building designers work in the early design stage' reported in Purup et al (2019). The authors used data from a range of semi-structured interviews with practicing architects to derive an explicit network of activities that designers navigate in during the early stages of the building design process. Furthermore, the interviews revealed a range of more concrete design activities within these activities that designers makes use during the design process. The interviewees was also asked to provide statements regarding desirable traits and functionality of a BPS tool for building design; based on these, the authors formulated a manifesto for the development of BPS tools fit to conform to any design activity conducted in the early stage. The manifesto is listed in the following:

- Fast modeling: use geometry already established architectural CAD models and make use of templates for setting up remaining input parameters.

- All geometry is possible: not only shoeboxes

- Fast and precise simulations: identify feasible tradeoffs, verify implementations

- CAD tool agnostic: the BEM tool should (at least) work in Rhino, SketchUp and Revit

- Intuitive output visualizations: output should immediately be perceived as relevant

- Process agnostic: supports typical design activities (i.e. not dicate a ceratin workflow)

- Connected to BIM data structures: generate functional requirements for detailed design, and enable interplay between tool and detailed design activities.

The development of the thermal simulation tool ICEbear, which in its BPS core is using an implementation of the simple hourly calculation (Purup and Petersen 2017) and a sophisticated but fast solar algorithm (Petersen et al 2018), is driven by this manifesto using the research framework described by Purup and Petersen (2019). The intention of this framework is to ensure that proposed initiatives to accommodate the manifesto is developed and tested together with potential end user in an iterative manner.

One of the concrete design activities identified by Purup et al (2019) was when designers choose to search for pictures of already realised building designs as inspiration to their own design. This paper reports on an investigation of whether it is useful to architects to have immediate access to parametric models linked to BPS tools that represents the façade concept of a chosen "Reference Picture" in the early stage of their design process.

\section{Method}

The study used the research framework defined by Purup and Petersen (2019) which is summarised in the following. 
As stated in the introduction, several procedures and methodologies for enhancing efficient use of thermal and daylight building simulation tools for proactive performance prediction in the early design stage has been proposed over the years but none of these suggestions seems to have gained any noticeable uptake in actual design practice. Furthermore, barriers that could explain the low uptake of BPS tools in the early design stage of professional design practice seems well-documented. Future research efforts should therefore focus on identifying solutions to overcome these barriers. For this, we need research methodologies that are fit for investigating the 'phenomenon of solutions' rather than the 'phenomenon of barriers'. Purup and Petersen (2019) have therefore proposed a research framework fit for research-based development of BPS tools conformed to fit common design practices in the early design stage. The proposed research framework is based on an extensive review of methods currently used in research of BPS for early stage design support, as well as a discussion of the relevance of approaches and methods from related research fields such as design research, social science, software development, and innovation research. The developed framework is illustrated in Figure 1 and consists of four main elements:

- the main research approach is the reflective researcher, who navigates the research based on continuous reflections on the theories of the research field, the chosen research methods and approaches as well as partial research outcomes (Brinkmann and Tanggaard, 2010);

- framing which is a rather specific articulation of the research theme, topic and question of interest related to the research objective to be investigated;
- a workflow procedure based on the theory of action research that structures research activities (planning, acting, reflecting and observing), secure scientific scrutiny and involve stakeholders (Kemmis \& McTaggert, 1993);

- a range of research activities related to various quantitative as well as qualitative research methods and approaches that could be deployed to study the framed research theme, topic and question from multiple perspectives and thereby enable multifaceted conclusions.

The practical workflow of the proposed framework initiate with the framing (Figure 1, top). Thereafter, the researcher start to do action research as a reflective researcher (Figure 1, center).

Figure 1 also summarizes how the described research framework was applied for the study presented in this paper. The first step was therefore to frame the research work by defining a research theme, topic and question for the investigation (Figure 1, top). Note that the research question formulated in Figure 1 is aligned with the intention of this paper as stated in the end of the introduction section.

Next step is to investigate the research question by doing action research as a reflective practitioner. In the planning phase of action research, it was decided to investigate the research question by developing a prototype and test this prototype in a focus group interview with practicing architects. This was followed by an acting phase, observation phase, and finally, reflection phase.

The following sections describes the development of the prototype and the interview guide for the subsequent test. 


\section{Framing:}

Research theme: BPS tool integration

Research topic(s): BPS to support decision-making in the design activity "Reference pictures"

Research question: Would it be useful to architects to have immediate access to parametric models - linked to BPS tools - that represents the façade concept of a chosen "reference picture"?

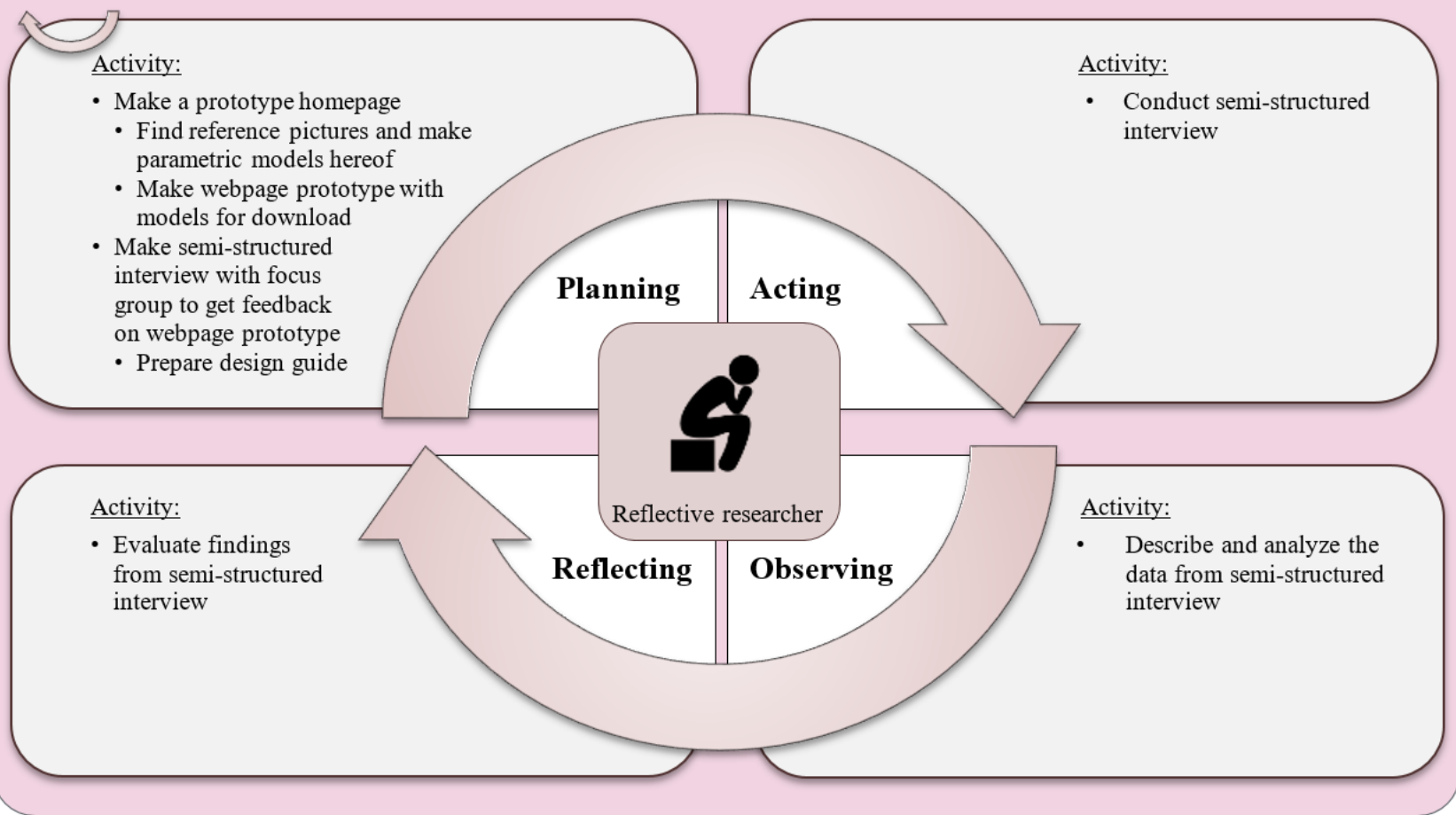

Figure 1: Research plan for this study.

\section{Prototype of 'Reference Pictures' database}

A reference picture of a façade is a picture taken from the interior and out or vice versa. In the prototype, a reference considered a picture of the exterior appearance of a building that also seems to be the most common perspective. It is also assumed that designers solely choose a reference picture due to some visual aesthetic attributes that are desirable for the new design. The first task in the development of the prototype was therefore to find a range of pictures with these traits. Fourteen graduate students attending a course in 'Integrated Energy Design’ at Aarhus University, Denmark, were asked each to find one reference picture of an office building façade. The students were asked to coordinate their choices to obtain a high diversity of façade designs.

Except from visual appearance, the reference pictures are totally disconnected from any concerns related to building performance such as quality of indoor environment (climate) and energy performance. Therefore, the students were asked to make a parametric model of a section of the façade in Rhino/Grasshopper with a room volume behind it. The parametric models should be able to resemble the visual appearance of reference pictures but the students should also parameterise the geometric parameters that governs the visual appearance of the reference picture (e.g. window size and placement).
Next, the students connected the parametric model to DIVA (2018) to calculate the hourly illuminance levels in a reference point (as input to daylight-controlled electrical lighting system in the thermal simulation). The model was also connected to the thermal simulation tool ICEbear which is an implementation of the simple hourly method in ISO 13790 (Purup and Petersen, 2017) combined with a new innovated solar algorithm (Petersen et al, 2018). The students were asked to set up the input for the simulations so that the model output fulfilled the criteria for operative temperatures in EN 15251 class II (allowed deviation of $5 \%$ ), a daylight autonomy of $50 \%$ in the lighting reference point, while approximating the criterion for low energy class according to the Danish building code (primary energy use of $33 \mathrm{kWh} / \mathrm{m}^{2} /$ year) using weather data from the Danish Design Reference Year 2013. These user-defined simulation inputs (thermal and daylight properties of constructions, HVAC settings, schedules for internal loads and HVAC, etc.) was saved in the simulation input template library of ICEbear which makes the inputs accessible and transferable. The students should also document that the outcome of their parametric models made physical sense by presenting an input/output analysis of some chosen parametric variations of their model (e.g. document that the effect of increasing the window size increased the amount of daylight in the reference point but also increased the need for cooling energy - as expected). 
Finally, all Rhino/grasshopper models connected to DIVA and ICEbear - including the simulation input template - generated by the students were compiled into a database with a prototype web-based interface where each reference picture was presented with a short description of the chosen geometrical parametric freedom of the model. The idea is then, that a building designer can download the Rhino/grasshopper model of a desirable façade design, manipulate its geometric variables and settings in the simulation template, and get fast and reliable performance evaluations of these manipulations because the downloaded model is already connected to DIVA and ICEbear. The building designer can also manipulate all variables in the simulation input template, if desired. Figure 2 illustrates an example of a model downloaded from the database. The figure shows the geometry rendered in Rhino, the Grasshopper environment where geometric façade parameters can be manipulated, the ICEbear interface where the remaining simulation inputs can be manipulated, and how ICEbear pass information about simulated performance (thermal comfort, daylight and energy use) to designers.

\section{Semi-structured interview}

A focus group interview with three practicing architects was planned to get practical feedback on the prototype. We first presented the background, idea and development of the prototype as described in the previous sections of this paper. Based on this introduction, we instigated a semi-structured interview. The architects were allowed to express their immediate opinions freely on any aspects related to the prototype that they found relevant. We had, however, formulated the interview guide shown in Table 1 beforehand to have some relevant questions to keep the interview going, if necessary. This interview guide followed the principles of Blommaert and Dong (2010), in which we motivate the subjects to tell narratives from their practice to provide examples of practical application. Thus, we also forced ourselves to keep an open mind .

The focus group agreed to have the interview audiorecorded for research purpose, and that observation notes were taken during the interview. Audio-recordings were transcripted (in Danish), and themes were categorized and analysed in relation to answering the research question. This is a methodological approach often used to report research findings in e.g. sociology studies (Brinkmann and Tanggaard, 2010).

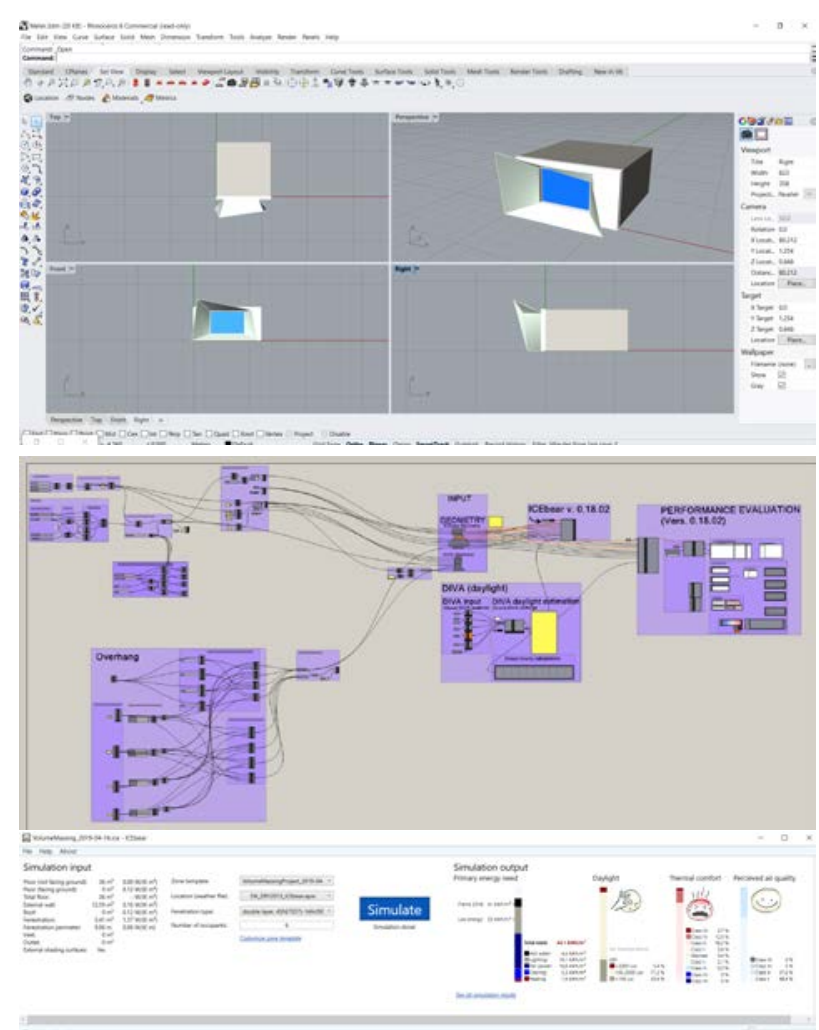

Figure 2: Screenshot of a model downloaded from the database prototype. Geometry shown in Rhino (top), the Grasshopper environment (middle), the ICEbear user interface, and ICEbear simulated performance output (bottom).

Table 1: Interview guide.

\begin{tabular}{|c|c|}
\hline Topics & Interview question \\
\hline $\begin{array}{c}\text { Usability of } \\
\text { database }\end{array}$ & $\begin{array}{l}\text { Could you imagine yourself make use of } \\
\text { such a database? } \\
\text { Why/Why not? How? }\end{array}$ \\
\hline $\begin{array}{l}\text { Reference } \\
\text { pictures }\end{array}$ & $\begin{array}{c}\text { Have you ever used reference pictures as } \\
\text { an input to your façade design process? } \\
\text { If yes, give an example of how you used } \\
\text { reference pictures. } \\
\text { Could you imagine yourself taking offset } \\
\text { in a reference picture already in the } \\
\text { database? } \\
\text { What makes a reference picture } \\
\text { inspirational? }\end{array}$ \\
\hline $\begin{array}{l}\text { Parametric } \\
\text { models }\end{array}$ & $\begin{array}{l}\text { Have you ever used parametric models in } \\
\text { your design process? How and for what? } \\
\text { Have you ever used parametric models } \\
\text { that were connected to BPS tools? Which } \\
\text { and how? } \\
\text { Regarding the prototype, would you } \\
\text { yourself work with the model of a chosen } \\
\text { reference picture or would you prefer an } \\
\text { engineer to do that? }\end{array}$ \\
\hline $\begin{array}{c}\text { Improvements } \\
\text { to the } \\
\text { prototype }\end{array}$ & $\begin{array}{l}\text { Do you have any reservations regarding } \\
\text { the prototype? } \\
\text { Any ideas for making the prototype more } \\
\text { useful/relevant? }\end{array}$ \\
\hline
\end{tabular}




\section{Results}

A total of 14 models of "Reference Pictures" were generated for the database. A complete overview of the reference pictures and corresponding parametric models connected to the aforementioned BPS tools are illustrated in Figure 3 (found in the end of the paper). Based on this database, a mock-up of the homepage was created (figure 4).

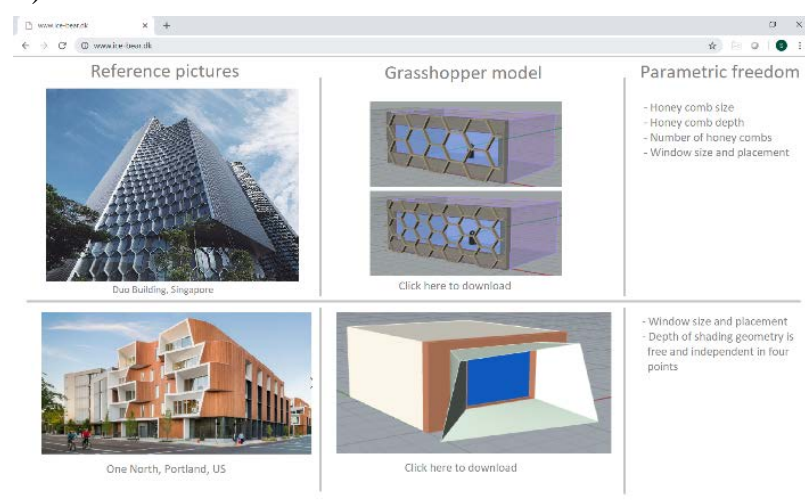

Figure 3: Screenshot of webpage mock-up with reference pictures and its corresponding parametric model and description of parametric freedom.

\section{Feedback on prototype}

The recorded results from the focus group interview following the interview guide presented in the method section is a transcription of the recorded dialogue (in Danish) and notes made by the researchers during the interview. These types of results are qualitative and descriptive by nature, and reporting them therefore also becomes qualitative and descriptive. The following is an extract of what we considered to be the essence of the feedback provided by the focus group subjects derived from the transcripted interviews and research notes.

The focus group participants stated that they often search for reference pictures in the early design stage. They identified the purpose of reference pictures as inspiration for "the mood and atmosphere of the project narrative", "identifying a direction of the design", and "the general form and materiality of the building”. As such, they believe that both form and materiality shown on a reference picture can serve as inspiration - in combination or independently.

The idea of having parametric models of reference pictures connected to BPS tools ready for design manipulation was intriguing to the focus group; however, the ability to manipulate the parameters defining the façade was not a feature needed to "create a mood/set the scene”. Instead, it would be very relevant to get some immediate graphical information about what they articulated as the performance potential (i.e. the geometrical boundaries for obtaining a certain level of energy, daylight and indoor climate performance) of the façade concept to inform the selection of reference pictures. The focus group ended up suggesting a new information layer next to the reference picture in the prototype of the database user interface depicted in Figure 3 that "somehow" illustrates the geometrical constraints of the façade concept with respect to energy and indoor climate performance without having to open any models and make simulations. Without being more specific on the graphical form of this, the focus group believed such an illustration of the performance potential could help the narrative of the design, e.g. to explain that the façade geometry varies with orientation to improve energy performance.

The option of having a predefined parametric model of a desirable façade concept identified with a reference picture was regarded as a great advantage once a certain façade concept was chosen for further analysis. The reason is the reduction of time usage for analysis. The focus group members had often experienced that questions about the energy and indoor climate performance of a certain concept requires that someone (usually an engineer) have to use days or weeks to model the concept before being able to provide any answers. In the meantime, architects may have dismissed the façade concept due to other architectural considerations making the modelling work futile. Having a predefined model would most likely avoid this frustrating situation while also provide a platform for better collaboration between architects and engineers. The focus group noted that they saw many opportunities for design activities at this stage. The predefined model could be used to test the effect of random ideas for adjustments as well as being used in an optimization process to identify a range possible solutions, e.g. as described in Lauridsen and Petersen (2014). It was emphasized that they would prefer to make these analyses in collaboration with a simulation specialist (engineer).

The focus group stressed that the parametric freedom of the models is essential but that the freedom should be respectful to the façade concept. It was suggested that further development of the prototype should include the division of façade concepts into overall typologies (e.g. "Horizontal Windows Bands", "Floor-to-Ceiling Windows", "Honeycomb Shadings", "Vertical External lamellas"). This could help designers find a parametric model that would fit to the concept of a reference picture which is not found in the database. It was also suggested that the reference pictures on the webpage was just examples of facades belonging to a certain typology, and that there was only one parametric model in the database representing this typology.

The focus group also suggested that the coloring of the parametric models should be neutral (e.g. white, transparent-white, light blue) to avoid that materiality would come in focus rather than the geometric opportunities of the façade concept/typology. In this matter the material would be a variable in the models through the simulation template describing U-values and reflectance as well.

\section{Conclusion}

This paper describes a prototype of a façade design database with parametric models connected to BPS tools intended for use in the early design stage. Feedback from practicing architects on the prototype indicates that 
building designers could benefit from having access to such a database. The feedback also provided valuable inputs for further development of a database relevant to practice. Especially two issues are deemed important for the future development of the database: 1) The database user interface should present the potentials of the façade concept in terms of energy and indoor climate performance graphically to inform the selection of a reference picture - without having to interact with the parametric model, and 2) the façade concepts could be grouped into typologies to ease the overview of the database, and - more importantly - enable designers to identify parametric model that would fit to the concept of a reference picture which is not found in the database.

\section{Acknowledgement}

The authors gratefully appreciate the funding for this study provided by the NIRAS ALECTIA Foundation and the Industrial Ph.D. program at Innovation Fund Denmark. Furthermore, we would like to extend our gratitude to C.F. Møller Architects for participating in the focus group interview.

\section{References}

Attia, S., Gratia E., De Herde, A. and J.L.M. Hensen (2012). Simulation-based decision support tool for early stages of zero-energy buildings. Energy and Building 49, 2-15.

Bleil de Souza, C. B. (2011). Contrasting paradigms of design thinking: The building thermal simulation tool user vs. the building designer. Automation in Construction 22, 112-122

Blommaert, J. and Dong J. (2010). Ethnographic fieldwork: A beginner's guide. Multilingual Matters. Bristol (UK).

Brinkmann, S. and Tanggaard L. (2010). Kvalitative metoder: en grundbog (in Danish), 1st edition, Hans Reitzels forlag, Copenhagen (Denmark).

DIVA-for-Rhino (2018) Solemma, US, http://diva4rhino.com/

Gerber, D. J. and S.E. Lin (2013). Designing in complexity: Simulation, integration, and multidisciplinary design optimization for architecture. Simulation 0(0), 1-24.

Kemmis, S. and McTaggart R. (1982). The Action Research Planner, Geelong, Deakin University.

Lauridsen P. K. B. \& Petersen S. (2014) Integrating indoor climate, daylight and energy simulations in parametric models and performance-based design. Proceedings from: Third International Workshop on Design in Civil and Environmental Engineering. Kgs. Lyngby (Denmark), 22-23 August 2014.

Lin, S-H and D.J. Gerber (2014). Evolutionary energy performance feedback for design: Multidiciplinary design optimization and performance boundaries for design decision support. Energy and Buildings 84, 426-441.
Petersen, S. 2011. Simulation-based support for integrated design of new low-energy office buildings. PhD diss., Danish Technical University (DTU). Kgs. Lyngy (Denmark).

Petersen, S., Bryder J., Levinsen K. and Strunge J. (2014) Method for Integrating Simulation-Based Support in the Building Design Process. Proceedings from: Third International Workshop on Design in Civil and Environmental Engineering. Kgs. Lyngby (Denmark), 22-23 August 2014.

Petersen S., Broholt T., Christensen L., Purup P.B. Thermal Performance Simulation of Complex Fenestration Systems in the Early Design Stage. Proceedings from BSO2018: 4th IBPSA-England Conference. Cambridge (England), 11-12 September 2018.

Purup P.B. and S. Petersen (2017). Rapid Simulation of Various Types of HVAC Systems in the Early Design Stage. Energy Procedia 122, 469-474.

Purup, P.B., S. Petersen (2019). Guidelines for the development of building performance simulation tools conformed to fit design practice. Automation in Construction. Submitted manuscript.

Purup, P.B., and S. Petersen (2020). Research framework for development of building performance simulation tools to support common design practice in the early design stage. Automation in Construction 109, 102966 


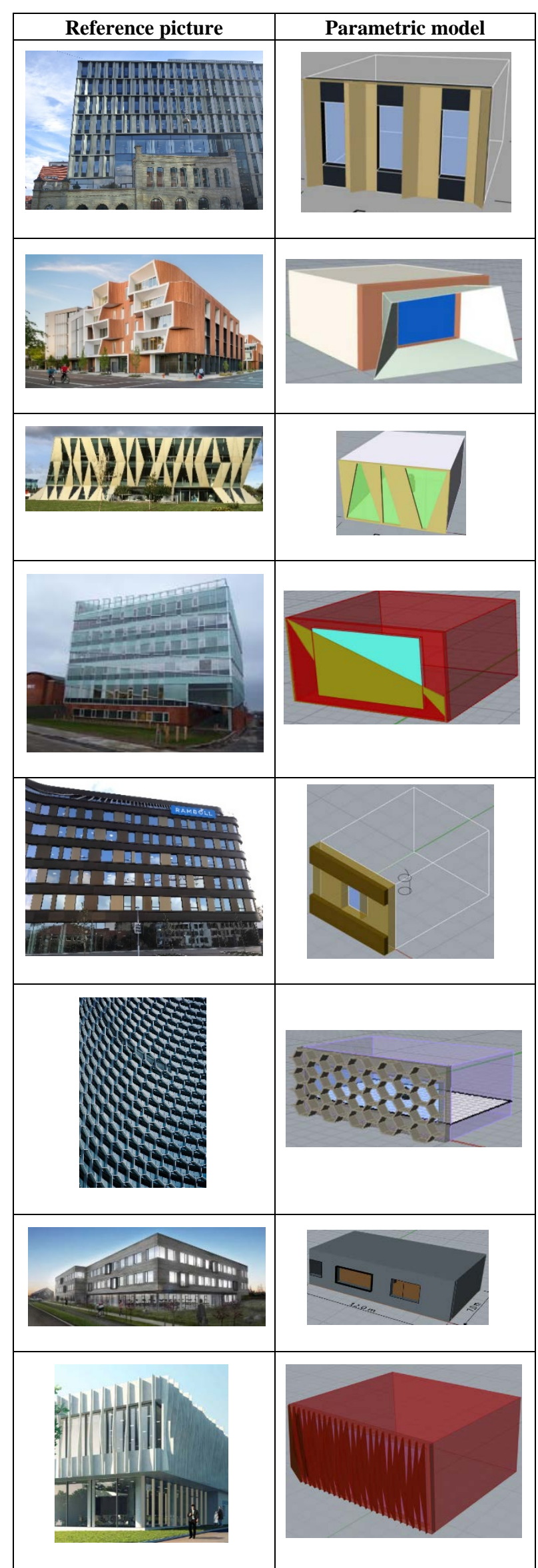

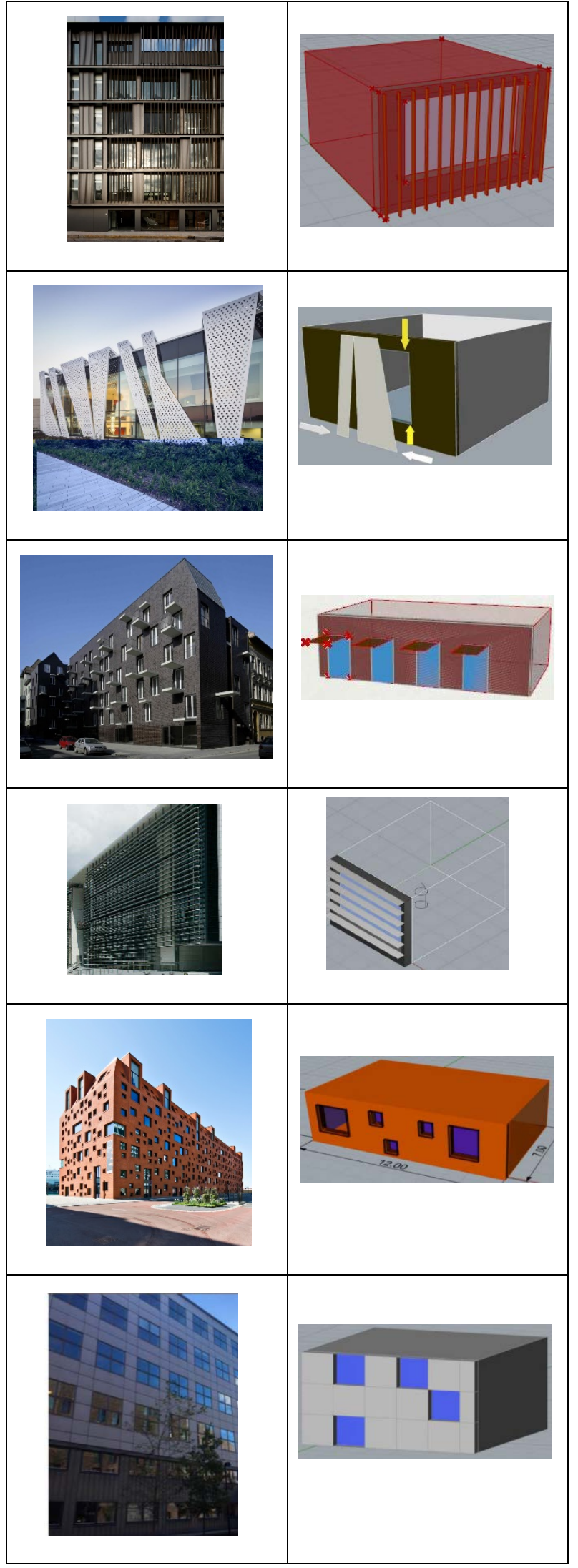

Figure 4: The reference pictures and their corresponding parametric models currently in the database. 